\title{
Surge-related topographic change of the glacier Sortebræ, East Greenland, derived from synthetic aperture radar interferometry
}

\author{
Hamish PRITCHARD, ${ }^{1,2 *}$ Tavi MURRAY, ${ }^{1}$ Tazio STROZZI, ${ }^{2,3}$ Stuart BARR, \\ ADRIAN LUCKMAN ${ }^{2}$ \\ ${ }^{1}$ School of Geography, University of Leeds, Leeds LS2 97T, England \\ E-mail:h.pritchard@bas.ac.uk \\ ${ }^{2}$ Department of Geography, University of Wales Swansea, Singleton Park, Swansea SA2 8PP, Wales \\ ${ }^{3}$ Gamma Remote Sensing, Thunstrasse 130, CH-3074 Muri (BE), Switzerland
}

\begin{abstract}
A major surge of the glacier complex of Sortebræ, East Greenland, occurred between 1992 and 1995. The impact of this surge on the topography of Sortebræ was examined through the production of a pre-surge (1981) digital elevation model (DEM) from interpolated digital map data, and a post-surge DEM from differential synthetic aperture radar interferometry using European Remote-sensing Satellite (ERS) imagery. The combined vertical error is typically $30-40 \mathrm{~m}$; however, downdraw of up to $270 \mathrm{~m}$ in the reservoir zone, and uplift of up to $145 \mathrm{~m}$ in the receiving zone were measured. The upper glacier reservoir area discharged in excess of $24.3 \pm 9.5 \mathrm{~km}^{3}$ volume over the surge, of which $\sim 12.5 \mathrm{~km}^{3}$ was stored in the advanced lower glacier, the balance being lost, predominantly to calving.
\end{abstract}

\section{INTRODUGTION}

Surge-type glaciers experience an internally driven flow instability which results in a periodic switch in their dynamic behaviour. Following a long period (decades) of slow, quiescent flow, ice accumulated in an upper glacier reservoir area is rapidly discharged to the lower glacier, at surge velocities up to 2 orders of magnitude greater than those in quiescence (e.g. Raymond, 1987). Immediately prior to the surge, average glacier surface gradient is at a maximum, generating high basal shear stress, particularly under the over-thickened reservoir area. Conversely, the immediate post-surge surface is at its shallowest mean gradient, and the reservoir at its thinnest. These two extremes in the surge cycle define the underlying conditions under which surges can initiate and terminate. At all other stages of ice storage, flow is stable to the annual fluctuations in meltwater supply and drainage evolution, believed to be the factors which control a surge (Clarke, 1987). The mechanisms by which surges initiate, propagate and terminate are poorly understood, and detailed and extensive quantitative information on the morphological development of glaciers over a surge cycle is required (Dolguishin and Osipova, 1975; Murray and others, 1998).

Surge-type glacier distribution is markedly clustered, and the extent of the East Greenland surge cluster has only recently been appreciated. This area has received little study, but at least 26 glaciers are believed to be of surge type,

* Present address: British Antarctic Survey, Natural Environment Research Council, Madingley Road, Cambridge CB3 0ET, England. though only four surges have been observed prior to that of Sortebræ (Weidick, 1988; Jiskoot and others, 2001). Sortebræ, a $52 \mathrm{~km}$ long tidewater-terminating glacier on the Blosseville Kyst of East Greenland, underwent a major surge lasting 3 years from 1992 to 1995 (Fig. 1). This resulted in heavy crevassing, moraine distortion and a frontal advance of $>5 \mathrm{~km}$ to the mouth of the fjord, which were detected in aerial photographs (Jiskoot and others, 2001) and synthetic aperture radar (SAR) imagery (Murray and others, 2002). Photogrammetric measurements of changes in glacier-margin elevation at 52 points in 1994 and 1995 have previously been used to characterize the downdraw of Sortebræ and some of its tributaries over the surge (Jiskoot and others, 2001), but detailed and spatially extensive topographic mapping of the post-surge glacier surface is lacking:

The technique of SAR interferometry (InSAR) now permits high-resolution, high-precision topographic mapping of remote areas (e.g. Zebker and Goldstein, 1986). This study employs a map of the elevation of the post-surge glacier surface created through InSAR, which is compared to the presurge surface derived from existing maps produced from 1981 aerial photographs by the Geological Survey of Denmark and Greenland (1996). The InSAR measurements extend the area of post-surge elevation data beyond that currently available (Jiskoot and others, 2001), to include Sortebræ West, Bulging Tributary East and the upper reaches of the Loop basins (Fig. 1) (glacier names are unofficial, after Jiskoot, 1999). The number of points measured is increased from 52 (Jiskoot and others, 2001) to approximately 250000 , at $40 \mathrm{~m}$ spacing (an area of $\sim 400 \mathrm{~km}^{2}$ ), and at a single post-surge date. High-resolution topographic data can also be employed to study flowrelated structures. 


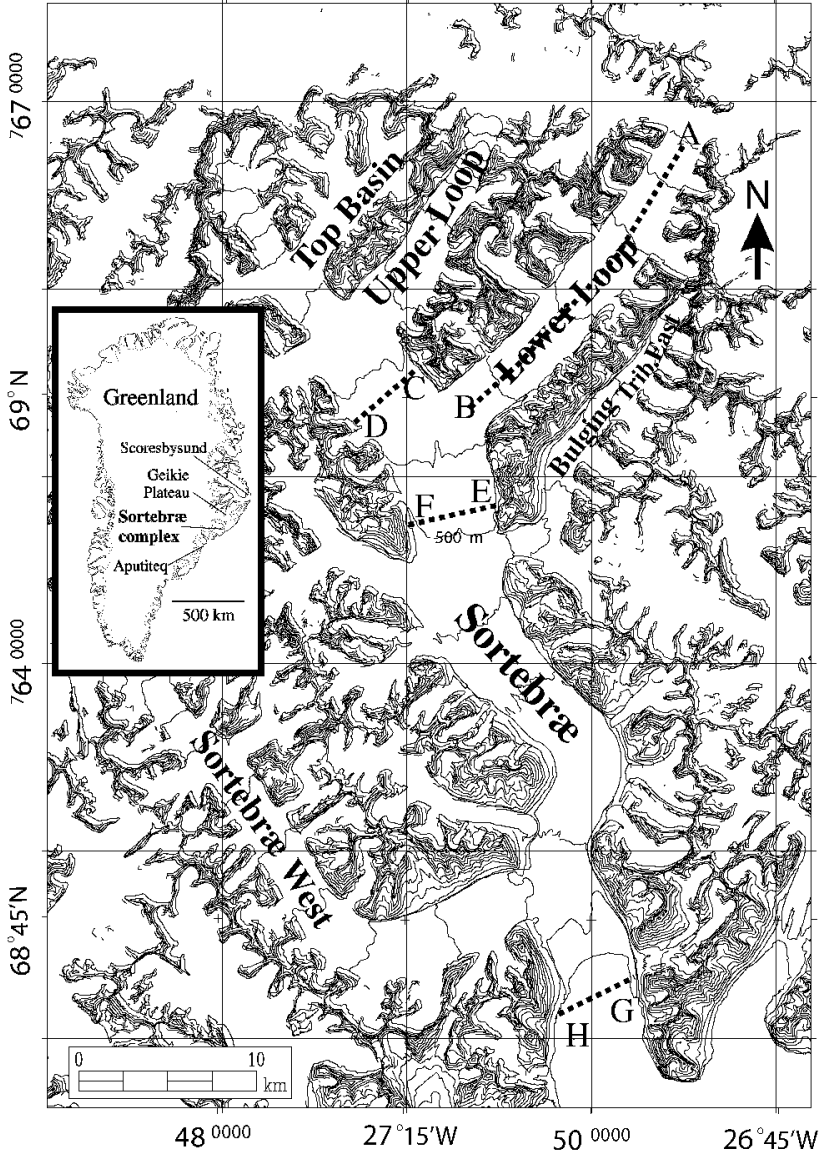

Fig. 1. The Sortebre complex and its location on the Blosseville Kyst of East Greenland. On-ice contours are shown for Sortebre and tributaries only, and are those used for trend-surface generation. Contour interval is $100 \mathrm{~m}$. Glacier names are unofficial, after Fiskoot (1999). Lines $A-B, C-D, E-F$ and $G-H$ represent the location of transects in Figures 4 and 5. Sortebre map based on 1:100 000 topographic maps compiled by the Geological Survey of Denmark and Greenland (GEUS), from 1981 aerial photographs and ground-control points supplied by the National Survey and Cadastre, Denmark.

\section{METHODS}

\subsection{Pre-surge DEM: Trend-surface contour inter- polation}

To determine the magnitude of the glacier elevation change over the surge, a pre-surge digital elevation model (DEM) was created from 1:100 000 scale digital data at 100 m contour interval from 1981 photographs (GEUS, 1996). The large vertical interval of these data gives rise to a typical contour spacing of $>4 \mathrm{~km}$ over the main trunk of Sortebræ, in contrast to the very dense spacing on surrounding valley walls (Fig. 1). In addition to their often sparse spacing, data along each contour are inherently of constant value, and distributed linearly (in this case at the $100 \mathrm{~m}$ elevation intervals described), with no data between contours. Such sparse and poorly distributed data result in problems in applying standard techniques to the interpolation of a continuous surface. For example, a local curve-fitting interpolation algorithm (ArcInfo's topogrid) performed poorly, introducing steps into the interpolated surface by modelling most of the inter-contour elevation change in close proximity to the contour locations. The data distribution was also inappropriate for inverse-distance weighting and kriging interpolation, which requires a locally varying sample of points (Oliver and others, 1989).

Trend surfaces have the potential to represent well the predominantly low relief and gradual longitudinal and transverse curvature which characterize the glacier profiles in this study. Such surfaces have been applied in interpolating data whose variability has a strong regional trend and a lesser local residual component, for example in the geological mapping of palaeosurfaces at a regional scale (Chorley and Haggett, 1965; Haining, 1987).

Trend surfaces were fitted through multiple regression to on-ice contours only, for individual glaciers and tributaries. The appropriate order of surface polynomial for each glacier was chosen through calculation of the root-mean-squared (rms) fit to the contours, and through visual assessment of the shape of the resulting surface. The point at which increases in polynomial order failed to produce substantial reductions in rms error was used to guide this selection (cf. Haining, 1987). Optimum fits to the glaciers studied were found with third- and fourth-order polynomials. The resulting continuous surfaces were gridded at $40 \mathrm{~m}$ spacing.

\subsection{Post-surge DEM: InSAR processing}

InSAR is an established technique capable of measuring both surface topography and surface displacement (e.g. Goldstein and others, 1988). Interferometric processing produces a measurement of phase difference at each pixel location in a pair of satellite SAR images acquired from orbits which are typically separated in time by a short interval, and in space by a baseline between orbits of up to hundreds of metres. Variations in phase difference result from the differences in range between the satellite and the surface. These range differences can result from displacement of the glacier surface over the time interval, from the slightly different viewing geometry associated with the baseline separation, and from the topography of the surface (Rignot and others, 1995).

In order to separate the topographic component of the phase change from the displacement component due to glacial flow, differential processing can be employed (e.g. Zebker and others, 1994). By assuming that the displacement due to flow is the same in two interferograms, it is possible to subtract one interferogram from the other to leave only the topographic component. The sensitivity of the phase measurement to topography is dependent on the spatial baseline between the positions of acquisition for the two images: larger baselines give greater topographic sensitivity but also reduce interferometric coherence. The accuracy of the topographic measurement is partially dependent on the validity of the assumption of constant displacement between the two interferograms used. Unaccounted-for changes in the magnitude of displacement will introduce a residual phase component, and hence error, into the data used for topographic mapping (Fatland and Lingle, 1998).

For this study, C-band SAR data from the European Space Agency (ESA) European Remote-sensing Satellites 1 and 2 (ERS-1/-2) tandem satellite mission, with 1 day separation between SAR images, were used. Tandem data are regularly available from April 1995 to July 1996. An interferogram of Sortebræ from late May 1995 showed that most of the glacier was incoherent due to high flow velocities, but by September 1995 the flow rate had fallen sufficiently for interferometric measurements to be made over most of the surface (Murray and others, 2002). This 
widespread, sudden deceleration of flow during summer 1995 is taken to indicate the end of the surge, but data from the following winter were used in order to maximize interferometric coherence. Data from track 396, frame 2205 were processed, for 7-8 January, 11-12 February and 17-18 March 1996, for which the perpendicular baselines were 6 , 132 and $142 \mathrm{~m}$ respectively. The differential baseline for the January-February pairs was $126 \mathrm{~m}$, and $10 \mathrm{~m}$ for the February-March pairs. Data were selected with reference to meteorological records (supplied by the Danish Meteorological Institute) from the closest recording stations at Aputiteq and Scoresbysund (Fig. 1), with the aim of selecting periods when weather-related surface change was slight, and hence coherence was maintained. Dates with belowfreezing temperatures, light winds and minimal precipitation were favoured.

In order to minimize the potential for significant changes in glacier flow velocity in the interferograms used for differential processing, only tandem-pair interferograms separated by the minimum 35 day repeat interval were used. Of the three winter interferometric pairs available, the January and February pairs showed the greatest coherence, and the differential baseline of $126 \mathrm{~m}$ gave an acceptable compromise between topographic sensitivity and coherence loss. Interferograms were 2 by 10 multilooked (spatially averaged by 2 pixels in range, 10 in azimuth) to achieve a compromise between spatial resolution and the reduction of phase noise, which facilitates phase unwrapping, the summation of phase cycles through image space (Zebker and others, 1994).

To relate the continuous series of phase cycles in an unwrapped interferogram to the continuous change in height on the ground, the phase rate must be calculated (Zebker and Goldstein, 1986). This is achieved by establishing ground-control points of known elevation within the image (Unwin and Wingham, 1997). The limited extent of the unwrapped area restricted the availability of ground control, which was extracted from the pre-surge 1:100000 scale photogrammetric maps (GEUS, 1996). In particular, none of the surveyed spot heights used in the map generation could be used because high-relief areas were not unwrapped, and furthermore, many glacier margins were obscured by layover and radar shadow. Control points were therefore restricted to successfully unwrapped glacier areas, where prominent features could be identified within the image and on the topographic map surveyed before the surge. Because the surface elevation of large areas of the glacier was known, or expected, to have changed substantially during the surge, control points were taken at the margins of tributaries visible in the SAR images but not involved in the surge. These tributaries were identified by surface pitting visible in the radar images, indicative of quiescent flow (Sturm, 1987); by photogrammetric spot measurements showing very little surge-related topographic change (Jiskoot and others, 2001); by analysis of the May 1995 (insurge) interferometric coherence image; and by studying the displacement maps produced alongside the topography results during differential InSAR, which highlighted areas of very slow flow.

\subsection{DEM rectification for height- and volume-change measurement}

In order to difference the pre- and post-surge surfaces, it was necessary to convert the InSAR DEM from SAR image

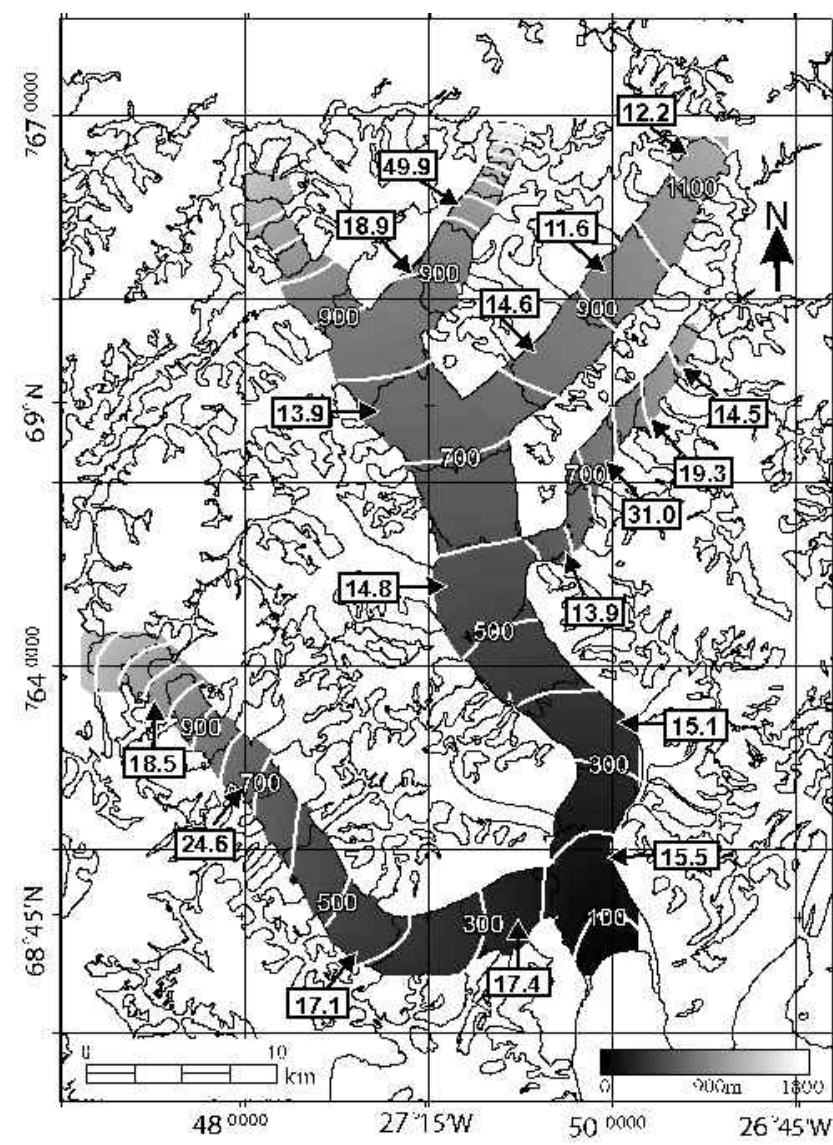

Fig. 2. Pre-surge trend-surface interpolated DEM of Sortebre, with glacier outlines for context. Numbers in boxes are the mean absolute errors for each error zone, in vertical metres, produced by comparison of the trend surface with contours lying within each zone. The division of each trend surface into error zones is discussed in the text. Shading showes elevation in metres above datum; contour interval is $100 \mathrm{~m}$, with trendsurface contours in white, original map contours in black ( space prohibits labelling of all contours). Sortebre map based on 1:100 000 topographic maps compiled by the GEUS, from 1981 aerial photographs and ground-control points supplied by the National Survey and Cadastre, Denmark.

geometry to the projection and datum of the map-derived DEM. An automated approach employing the precision orbital data available for the SAR images and the existing topographic information was used (Werner and others, 2001).

The initial bilinear polynomial for conversion from SAR to map geometry was established from the ERS precision orbit parameters. However, small errors in the orbital data can introduce relatively large positional errors in the rectified product. In order to refine the rectification, a further DEM was interpolated from the digital contour data, in this case for the full area surrounding Sortebræ that is also covered by the SAR data. Because this larger area is dominated by steep slopes and high relief, and hence has densely spaced contours, a curve-fitting interpolation algorithm (ArcInfo's topogrid) was applied to produce a continuous gridded DEM. The SAR images used in this study were then rectified to a SAR image modelled from this DEM, using an automated cross-correlation of intensity technique to refine the initial rectification model. The trend surfaces and InSAR DEM were differenced to produce a difference DEM at $40 \mathrm{~m}$ pixel spacing for most of the surface 
Table 1. Trend-surface polynomial order and resulting rms fit to contours, and an estimate of the overall combined elevation error which would result from the differencing of the trendsurface and InSAR DEMs (contour error $( \pm 10 \mathrm{~m}$ ) is combined with trend-surface rms as a root-of-sum-of-squares, and the InSAR error $( \pm 20 \mathrm{~m})$ is added to this)

\begin{tabular}{lccc}
\hline Glacier & $\begin{array}{l}\text { Trend } \\
\text { order }\end{array}$ & $\begin{array}{c}\text { Trend- } \\
\text { surface rms }\end{array}$ & $\begin{array}{c}\text { Combined } \\
\text { errorestimate }\end{array}$
\end{tabular}

$\mathrm{m}$

$\mathrm{m}$

Sortebræ Main

Sortebræ West

Lower Loop

Upper Loop

Bulging Tributary East

$\begin{array}{ll}4 & 16 \\ 4 & 27 \\ 3 & 10 \\ 3 & 34 \\ 4 & 17\end{array}$

39

49

34

55

40

of Sortebræ. The height-change and area information in this DEM was then used to calculate glacier volume change.

\section{RESULTS}

\subsection{The pre-surge surface}

The 1981 pre-surge surface was interpolated to a regular gridded DEM for the full area of the main trunk and the tributaries of Sortebræ also covered by the InSAR DEM (Fig. 2).

The contour data on which the pre-surge surface is based have an estimated $\pm 10 \mathrm{~m}$ error (personal communication from H. Jepsen, 2002). Additionally, the trend surfaces have fit errors to the contour data, expressed as rms error values. Table 1 shows the overall trend-surface rms error values which were used in selection of the polynomial order and the orders which most successfully modelled the longitudinal and lateral surface topographic trends.

The overall rms error values do not represent the distribution of error in each surface because the topography is more readily represented by the polynomials used in some parts of the glacier than in others. For the purpose of characterizing this spatial distribution, error "zones" were defined for each surface. Trend-surface height values were extracted along each contour and differenced from the contour elevation. Error zones were selected according to the nature of the errors for adjacent contours, where a zone was characterized by contour means and standard deviations of error with greater intra-zone than inter-zone similarity. The error value assigned to a zone was calculated by taking the absolute difference in elevation of the trend surface from the contour elevation for every trend-surface pixel along each contour in a zone (Fig. 2). The mean of all of these absolute differences (for each zone) was then calculated. This value was then combined with the contour error by taking the root of the sum of the squares. The combined trend-surface error was then summed with the InSAR error to give a total heightchange error. These localized errors, rather than those for the whole surface, were used when calculating volume-change error values (Table 1). This improves the accuracy of the volume-change error estimates at a local scale.

\subsection{The post-surge surface}

The post-surge surface elevation was successfully mapped

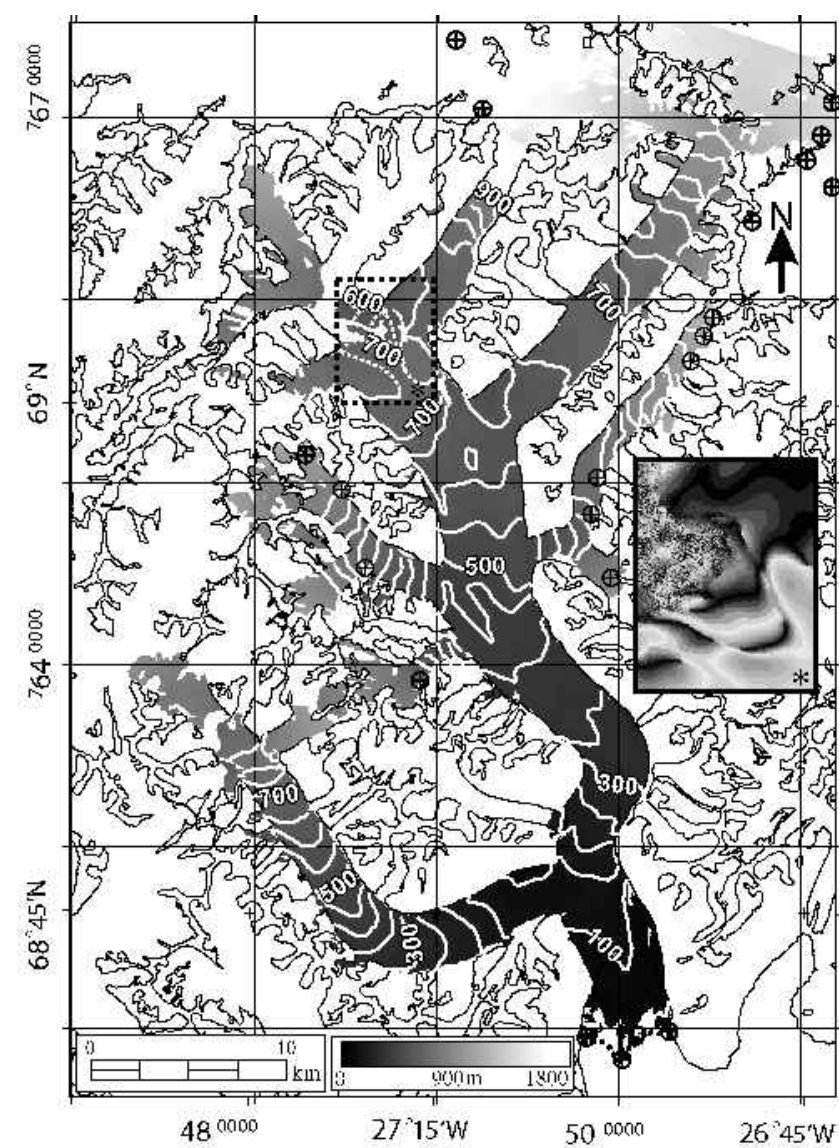

Fig. 3. Post-surge InSAR DEM of Sortebre. Crossed circles show the location of control points. Shading showe elevation in metres above datum; contour interval is $50 \mathrm{~m}$. The detail inset (*) showes a section of the very short-baseline differential interferogram from the February and March InSAR pairs. The fringes visible indicate an acceleration of flow over this period, and contours here (dotted) are unreliable. Up-glacier of this, the interferogram is incoherent, and no fringes are present, a result of persistently fast flow in the Top Basin tributary.

over most of the main trunk and the major tributaries, Sortebræ West, Bulging Tributary East and the Lower and Upper Loop basins (Fig. 3). However, coverage is limited in the upper reaches of the main trunk and Upper Loop, and absent over the Top Basin (Fig. 3). The high resolution of the post-surge DEM permits the study of localized glacier topographic features.

After the surge, the upper main trunk of Sortebræ (transects $\mathrm{C}-\mathrm{D}$ and $\mathrm{E}-\mathrm{F}$ in Fig. 1) can be seen to be dominated by two adjacent flow units, each with a lateral convexity, separated by a medial trough which corresponds with the visible medial moraines (Fig. 4). In contrast, the topography of the snout region, which has advanced into the fjord, is characterized by a prominent medial ridge, with depressions to either side, with an amplitude of 50-70 m (Fig. 4, transect G-H, Fig. 1). This medial ridge extends to the front, and coincides with the most advanced section of the glacier front at the time of imaging. The height of the late-surge ice cliff adjacent to the medial ridge was $24-34 \mathrm{~m}$. The Lower Loop basin can be seen to exhibit an undulating longitudinal post-surge topography (Fig. 5).

\subsubsection{Extent of InSAR coverage}

Significant limitations to InSAR topographic mapping of Sortebræ were encountered due to the nature of the study 

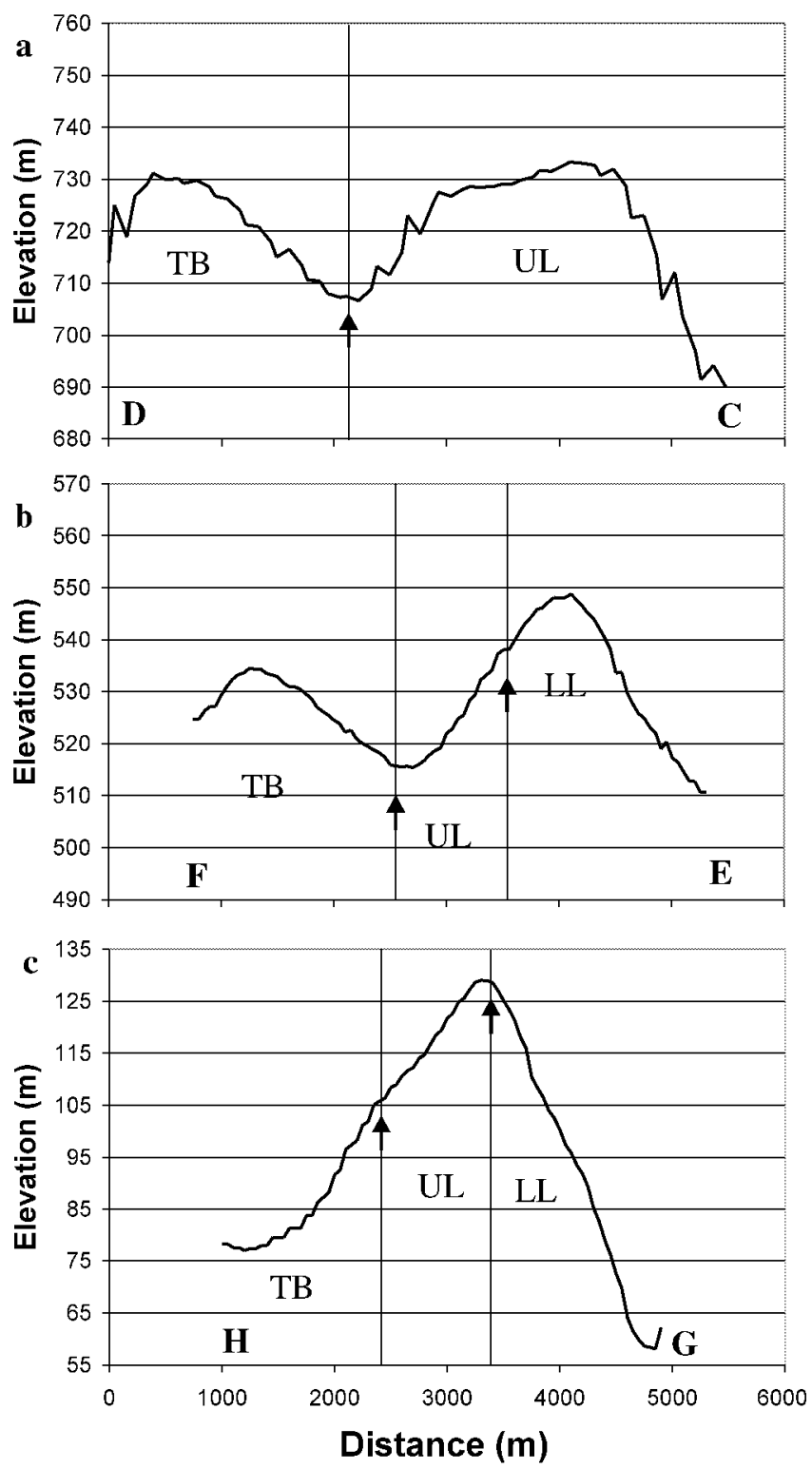

Fig. 4. Cross-profiles of elevation across (a) upper Sortebre main trunk (between points $C$ and $D$ in Fig. 1);(b) midmain trunk ( E-F; Fig. 1); (c) the advanced front of Sortebre ( $G-H$; Fig. 1) (flow is out of page). UL denotes the Upper Loop flow unit, LL the Lower Loop unit, and TB the Top Basin unit, with arrows indicating the locations of principal medial moraines. The cross-profile of the advanced section (c) appears to reflect the basal topography rather than individual flow units.

area. Phase unwrapping was hindered by areas of low coherence at lateral margins, which likely resulted from surface change, including rotation due to shear (Goldstein and others, 1988). In addition, the Sortebræ area is characterized by very high relief, with typical slope angles of $\sim 60^{\circ}$. These slopes caused extensive radar layover in the images, which introduced abrupt phase jumps that could not be successfully unwrapped (De Fazio and Vinelli, 1993; Zebker and others, 1994), and as a result it was not possible to map beyond the low-relief glacier surfaces (Fig. 3).

The spatial extent of the InSAR DEM is also limited by the low coherence of the Top Basin tributary above approximately $800 \mathrm{~m}$ elevation (Fig. 3). Given the generally good coherence in adjacent areas and on adjacent glaciers, this is attributed to high ice-flow velocities rather than to snow

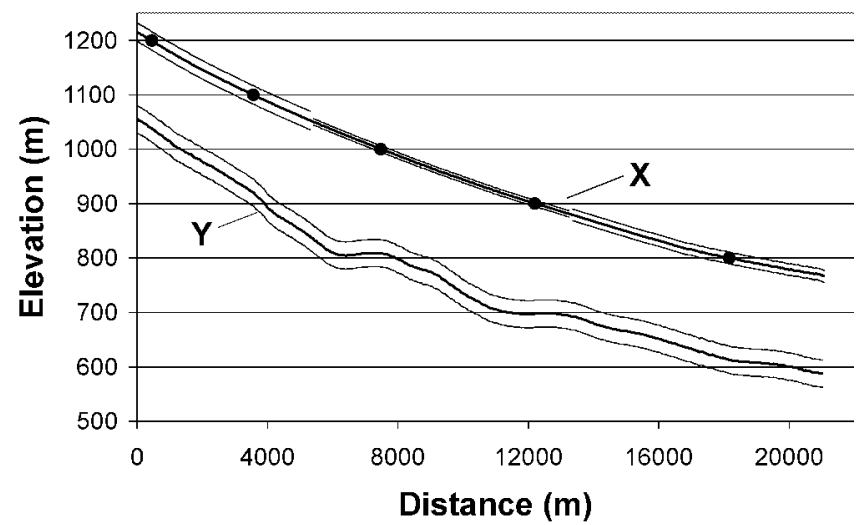

Fig. 5. Long profiles of the pre-surge $(X)$ and post-surge $(Y)$ elevation along the centre line of a section of the Lower Loop tributary, from point A to point B in Figure 1. The interpolated trend surface is depicted by $X$, with the magnitude of combined error associated with the fit to the contours and the contour error shown. Black dots show contour location. $Y$ showes the wavy post-surge InSAR surface, with estimated error (it is not known whether waves existed in the pre-surge surface).

accumulation or melt. This localized, incoherent area of fast flow which persisted through winter 1996 is in contrast to the widespread coherent conditions which rapidly became established following the surge termination during the previous summer.

Between the confluences of the rapidly flowing Top Basin and the Upper Loop basin tributaries with the quiescent trunk (Fig. 1), a large apparent downdraw and substantial surface bulge were observed in the DEM (Fig. 3). The unexpected magnitude and nature of this feature were further examined through the generation of another differential interferogram for the February-March datasets. This differential interferogram has a very short baseline $(10 \mathrm{~m})$, and hence has very little topographic sensitivity (Zebker and others, 1994). With differential processing to remove constant velocity, the resulting interferogram should show almost no change in phase over the image. Instead a series of fringes indicating rapid change in phase was found in the very short baseline interferogram in the area of the surface "bulge" (insert in Fig. 3). Rather than resulting from a large change in surface height in this region, this phase change resulted from a relatively small change in surface flow rate, i.e. a local failure in the constant velocity assumption (GVA). This change resulted in an increase in radar range to the surface at a rate of $\sim 0.06-0.08 \mathrm{~m} \mathrm{~d}^{-1}$ in slant range (equivalent to a horizontal, ground-range speed-up of 0.14$0.22 \mathrm{~m} \mathrm{~d}^{-1}$, or a vertical lowering of $0.06-0.09 \mathrm{~m} \mathrm{~d}^{-1}$ ) in the 35 days between the February and March data. The introduction of unaccounted-for velocity-related phase cycles in this area in the January-February data is likely to have led to the propagation of a constant underestimate of height by approximately $110 \mathrm{~m}$ over the relatively small basins above the zone of acceleration; thus the elevation data from these basins were not used in this study. This zone of surface-flow change is found immediately down-glacier of the incoherent Top Basin tributary, which is interpreted as remaining in surge during winter 1995 (Murray and others, 2002). It is therefore unlikely that surface lowering occurred here, under a compressive regime, and more likely that it was the down-glacier flow rate that increased. 


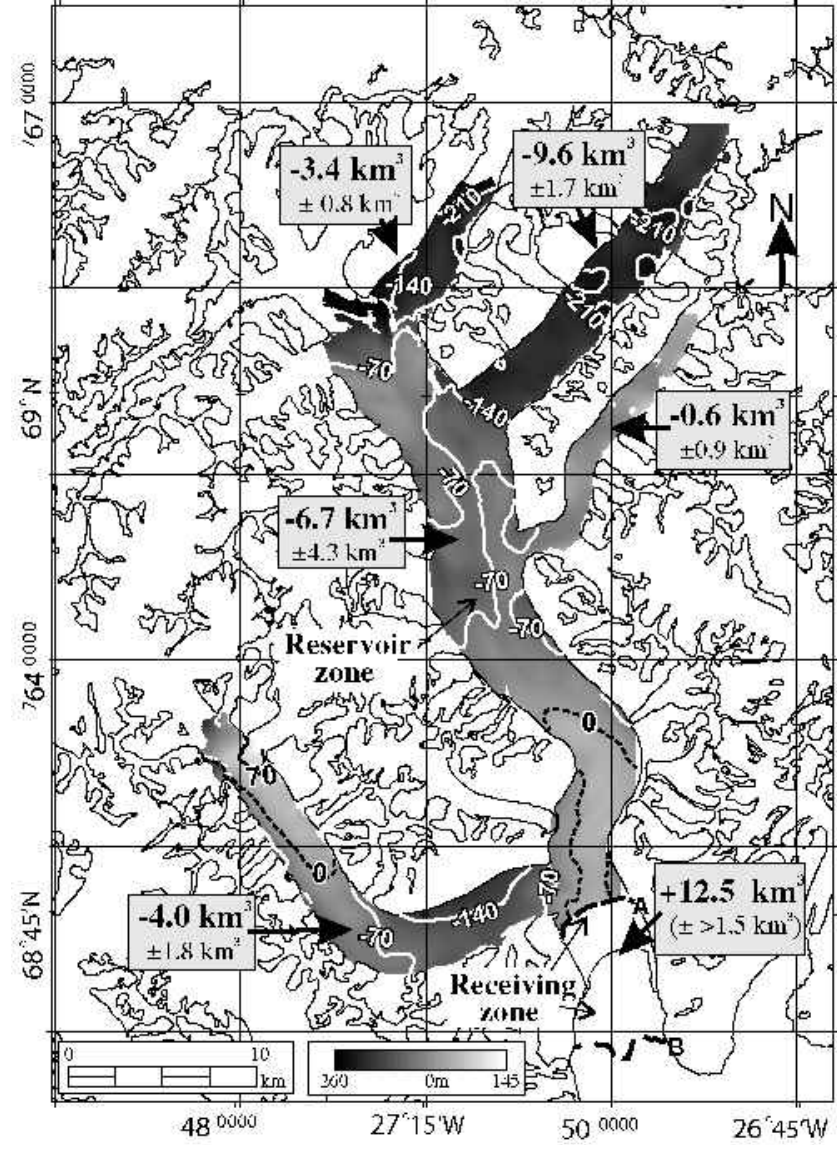

Fig. 6. Difference DEM showing the change in surface elevation resulting from the surge. Boxes give the volumes of ice lost and gained in each region in $\mathrm{km}^{3}$. Shading shows surface elevation change in metres; contour interval is $70 \mathrm{~m}$, the minimum interval given the estimated error (Kraus, 1993). The dashed lines show the 1992 (A) and 1996 (B) margins; the dotted contour shows the zero-change line crossing the trunk between 200 and $300 \mathrm{~m}$ altitude (ELA is 1100-1200 m). On the main trunk, this defines the receiving zone, with the reservoir zone lying up-glacier of this. Slight thickening also occurred above the zero-change line on Sortebre West. The step visible at the confluence of Lower Loop tributary results from the mismatch of the poorly constrained edges of two separate pre-surge trend surfaces at this point, although a genuine, less abrupt step also exists in the post-surge surface.

\subsubsection{Error in the InSAR DEM}

Interferometric processing is capable of producing elevation measurements with centimetre-scale relative precision (Zebker and Goldstein, 1986). Absolute height accuracy is, however, subject to degradation in a number of ways, including errors in the estimated satellite baseline, noise in the measurements of phase due to system limitations and loss of coherence, and variations in wave propagation rate through the atmosphere due to varying humidity (e.g. Zebker and others, 1994; Unwin and Wingham, 1997; Mohr and others, 1998). Errors in baseline can introduce large systematic errors in elevation, though with sufficient ground-control points this can be reduced to $<5 \mathrm{~m}$ vertical $\mathrm{rms}$ error (Unwin and Wingham, 1997). In the absence of phase noise, six control points of $5 \mathrm{~m}$ rms error will give a DEM rms height accuracy of $\sim 5 \mathrm{~m}$ (Zebker and others, 1994). Baseline separation will itself introduce a coherence-loss related error, although for a $126 \mathrm{~m}$ baseline averaged with 10 looks this is $<1.8 \mathrm{~m}$ rms ver- tical (Zebker and others, 1994). North of $60^{\circ} \mathrm{N}$, significant signal delay due to atmospheric water vapour is believed to be unlikely during winter (Fatland and Lingle, 1998; Mohr and others, 1998). An additional source of elevation error can occur over glacial surfaces in the absence of meltwater, where the air-ice or air-snow dielectric contrast is relatively low, and signal penetration into the surface occurs (Fatland and Lingle, 1998) (see section 4.1).

As discussed above, the theoretical limit to InSAR DEMs using ERS data is an rms error of approximately $5 \mathrm{~m}$, but with the error sources described, it is estimated that $20 \mathrm{~m} \mathrm{rms}$ is a more reasonable value for glacierized areas (Zebker and others, 1994; Fatland and Lingle, 1998). In this study, 21 height control points were used (Fig. 3), and the rms fit to these points was $16.6 \mathrm{~m}$. With spatially variable coherence and penetration effects, an rms error of $20 \mathrm{~m}$ is probably more realistic, and is used in error estimates.

\subsection{Changes in surface elevation and glacier volume}

Differencing of the rectified pre- and post-surge DEMs reveals the glacier surface elevation change over the period 1981-96 (Fig. 6), and depicts the reservoir and receiving zones of the glacier. Coverage is limited by the extent of the post-surge (InSAR) DEM; for example, ice loss in the top basin could not be measured.

\subsubsection{Combined error}

The errors resulting from differencing of the pre-surge trend surfaces and the post-surge InSAR surface were calculated using the constant estimated InSAR error, and the local, zone-by-zone trend-surface error described previously. Because errors in both DEMs are thought to be predominantly systematic, combined errors were calculated by summing those for each (Squires, 1976) (Fig. 6). The comparison presented in section 4.4 suggests that this is a conservative estimate. As a guide, an estimate of the combined error produced using each overall trend-surface rms and the InSAR surface error has been calculated (Table 1). The lowest errors were found on Sortebræ main trunk, and the Lower Loop basin, covering most of the surge-affected area.

\subsubsection{Reservoir zone downdraw}

The reservoir zone of Sortebræ (up-glacier of the zerochange contour in Fig. 6), including the upper main trunk, and the Upper and Lower Loop basins (Fig. 1), experienced substantial ice loss over the surge, with the greatest measurable downdraw occurring in the Loop basin tributaries (Fig. 6). Mean downdraw for the lower $70 \%$ of the Upper Loop basin measurable through InSAR was $180 \pm 39$ m (measured maximum $274 \mathrm{~m}$, minimum $79 \mathrm{~m}$ ). In the Lower Loop, mean downdraw from this study was $179 \pm 33 \mathrm{~m}$, maximum $223 \mathrm{~m}$, minimum $112 \mathrm{~m}$.

Bulging Tributary East is dominated by downdraw immediately up-glacier of the confluence with Sortebræ. Elsewhere, the surface remained largely unchanged, as this tributary did not become actively involved in the surge. The difference DEM of Sortebræ West shows a zone of surface downdraw ranging from $117 \pm 37 \mathrm{~m}$ immediately up-glacier of the confluence with Sortebræ and decreasing linearly to zero about $15 \mathrm{~km}$ up-glacier (Fig. 6); mean downdraw in this zone was $86 \pm 37 \mathrm{~m}$ over an area of $47 \mathrm{~km}^{2}$. Immediately upglacier of this, slight thickening occurred. 


\section{DISCUSSION}

\subsection{Glacier surface definition}

For comparison of glacier surface elevations acquired using photogrammetric and radar techniques, it is necessary to consider the nature of the surface as imaged by each. In order to limit loss of coherence due to surface change, winter InSAR data were acquired from dates when it was expected that temperatures were well below freezing, and Sortebræ was covered by a dry snow pack. This is significant because radar penetration into dry snow and cold ice leads to the measurement of a "surface" at some depth below the visible snow or ice surface. In contrast, the pre-surge DEM was derived from photographs taken in late summer, when the winter snow pack was absent.

The problem of SAR penetration is mitigated by the location of the height control points (of photogrammetric origin) used in this study, which were taken on glacier surfaces only. Rock elevations were not used, and thus the penetration error in the InSAR DEM has to some extent been systematically cancelled out on the glaciers. The subsurface defined by the mean locus of backscatter has been assigned the absolute height of the visible surface through use of control points which are located only where penetration occurs. The heights reported in the InSAR DEM should therefore approximate the true visible surface height.

The maps of the pre-surge surface were produced from late-summer photographs from 1981, so it is likely that the photogrammetrically derived elevations below the equilibrium-line altitude (ELA) correspond very closely to the true ice surface. Above the ELA, a representative glacier surface is harder to define, as snowpack thickness varies seasonally, and grades through firn to glacier ice at some depth. Such a surface is, furthermore, difficult to map photogrammetrically due to low surface contrast (Fox, 1995). The mapped areas of topographic change lie, however, almost entirely below the ELA. A further consideration is that the surface topography may have changed between the 1981 mapping and the 1992 surge initiation. It is not possible to quantify the magnitude of any such change, though it is expected to be small relative to the errors described.

\subsection{Post-surge surface characteristics}

\subsubsection{Sortebre main trunk}

Medial moraines visible between the Upper Loop and Top Basin flow units, and the topographic expression of these flow units visible within the main trunk of Sortebræ (Fig. 4) reveal that both participated in the surge. Neither tributary is sheared off, but bulging of the moraine by flow from the Top Basin unit indicates that this tributary became increasingly significant late in the surge. The Upper Loop unit loses its topographic distinction further down-glacier, under the influence of the confluent Lower Loop flow. From below this tributary to below the confluence of Sortebræ West, the surface topography is dominated by one laterally convex unit from the Top Basin, and another resulting from the combined flow from the Upper Loop and Lower Loop tributaries (Fig. 4), and these are separated by a medial trough. This indicates that these sources surged concurrently and for a similar duration.

The presence of a medial ridge in the surface above the glacier snout (Fig. 4), which corresponds with the area of least frontal retreat in late surge, suggests that Sortebræ advanced over a substantial submarine longitudinal ridge that coincides with the large medial moraine demarcating the observed flow-unit boundary described above. A time series of SAR images shows rapid late-surge frontal retreat either side of this central ridge (Murray and others, 2002), where ice remains "pinned". The grounding of the snout along this ridge, and the consequent lack of tidal effects on surface elevation, is supported by the maintenance of interferometric coherence in this area (Fig. 3). Loss of coherence, relatively rapid retreat and lower elevation over the snout on either side of the ridge suggest that these sections lie in deeper water and may not be fully grounded. This conjecture is supported by the presence of fringes near the front on either side of the ridge, in the short-baseline February-March differential interferogram, indicating localized changes in velocity. Such conditions resemble the "low-effective-pressure" zone identified as significant in permitting very rapid advance of tidewater margins under longitudinal stress in surging Svalbard glaciers (Hodgkins and Dowdeswell, 1994).

\subsubsection{Lower Loop basin}

The Lower Loop basin has been interpreted as the location of surge initiation (Jiskoot and others, 2001). This interpretation was made based on analysis of crevasse orientation, from which it is suggested that the surge began approximately halfway up-glacier from the confluence with Sortebræ. A relatively early termination of the surge here is indicated by coherence images produced from May 1995 interferograms which show some coherence on this tributary, in contrast to the main trunk.

Undulations in the late-surge surface of the Lower Loop basin were first observed in aerial photographs, and were suggested to be the result of kinematic waves (Jiskoot and others, 2001). From the InSAR DEM, the post-surge undulations on the Lower Loop can be seen to have an amplitude range of $10-120 \mathrm{~m}$, with a waveleng th of 3.5-4.5 km (Fig. 5), though they are not systematically aligned perpendicular to the down-glacier direction. Instead, wave location and amplitude vary between the eastern and western sides of the Lower Loop tributary, which originate as separate flow units from independent source areas (Fig. 1). The western flow-unit waves appear to be displaced down-glacier, suggesting that the two units may have had distinct flow regimes, at least in late surge.

\subsection{Surface elevation change: comparison with an earlier study}

The surface elevation-change measurements from winter 1996 data described in this paper can be compared to photogrammetric measurements from summer 1995, undertaken by Jiskoot and others (2001). Downdraw at a point on the northern margin of the Upper Loop basin was measured as $215 \pm 39 \mathrm{~m}$ by this study, and $219 \pm 10.3 \mathrm{~m}$ by photogrammetry (Jiskoot and others, 2001). On the southern margin, the measurements were $183 \pm 39$ and $191 \pm 10.3 \mathrm{~m}$, respectively, and at the confluence with Sortebræ, $48 \pm 39$ and $60 \pm 0.7 \mathrm{~m}$ of downdraw, respectively, in this area of high estimated trend-surface error. The results of the two studies agree within the error estimates, and this comparison suggests that the elevationchange errors in this study may actually be lower than the error estimates quoted.

The difference DEM for the Lower Loop basin, however, shows discrepancies with the earlier photogrammetric 
measurements (Jiskoot and others, 2001). InSAR-derived downdraw at 17 points taken on this tributary is consistently greater, by an average of $80 \mathrm{~m}$, which exceeds the combined error of the two studies. However, the photogrammetric measurements were made at the margin from August 1994 photographs, 18 months before the InSAR ones. It is likely that downdraw continued for up to 1 year after this date, until the surge termination during summer 1995, and led to a lower final surface. In addition, the relatively high relief of marginal zones is likely to be least well represented by a trend surface unconstrained by elevation data beyond the ice margin.

The Lower Loop tributary is fed by a large, poorly mapped eastern accumulation area, and a western distributary of the nearby Geikie Plateau, which also branches to feed the Upper Loop tributary. Although not included in the trend surface interpolation, some downdraw in the flow units which feed Lower Loop is detectable, relative to mapped contours, up to an elevation of 1600-1700 $\mathrm{m}$ to the east, and up to $\sim 1800 \mathrm{~m}$ to the west, though the eastern downdraw area is spatially much more extensive. In contrast, the effect of the surge of Upper Loop does not appear to have propagated above the icefall which links it to the Geikie Plateau.

\subsection{Overall volume change and ice loss}

\subsubsection{Reservoir zone volume loss}

The total volume of ice lost from the measured $226 \mathrm{~km}^{2}$ of the reservoir zone (calculated as the product of downdraw and zone area from the DEM) is estimated as $24.3 \pm 9.5$ $\mathrm{km}^{3}$. These measurements cover $\sim 70 \%$ of the estimated area of the reservoir zone. Jiskoot and others (2001) apply a $10 \%$ correction to glacier volume measurements of Sortebræ to account for the porosity introduced by heavy crevassing in surge. When this is applied, the volume loss was $21.9 \pm 8.6 \mathrm{~km}^{3}$, which represents a minimum for the Sortebræ complex because those upper basins remaining in surge, or lying above the area of CVA failure, could not be included in this study.

\subsubsection{Receiving-zone volume gain}

Recently obtained images of Sortebræ shortly before the surge in summer 1992 show that a retreat of $\sim 2.5 \mathrm{~km}$ from the 1981 mapped margin had occurred, and the maximum surge advance was $9-10 \mathrm{~km}$. Taking this into account, glacier volume gain in the lower trunk (down-glacier of the zero-change contour) is dominated by the estimated volume of ice stored in the $31.6 \mathrm{~km}^{2}$ of the glacier advance, rather than that stored through lower-glacier thickening above the pre-surge margin (Fig. 6). Mean thickening above the pre-surge margin was measured as $18 \mathrm{~m}( \pm 36 \mathrm{~m})$ over a $24 \mathrm{~km}^{2}$ area, giving a volume gain of $\sim 0.4 \pm 0.9 \mathrm{~km}^{3}$.

In order to calculate the volume of ice stored by the advance of Sortebræ into the fjord, the fjord depth was estimated. The late-surge calving ice cliff adjacent to the medial ridge is $24-34 \mathrm{~m}$ high in the InSAR DEM, which can be compared to a photogrammetric measurement of $24 \mathrm{~m}$ (and $59 \mathrm{~m}$ over the ridge) (Jiskoot and others, 2001). If floating, this would indicate an overall ice-cliff thickness of approximately $240-340 \mathrm{~m}$. This is in keeping with estimates from bathymetric maps of a fjord depth of approximately $300 \mathrm{~m}$ (Jiskoot and others, 2001). Furthermore, seven large icebergs are visible in front of the retreating
Table 2. The surge of Sortebre compared to surges for which similar results are available (after Fiskoot, 1999)

\begin{tabular}{lccc}
\hline Glacier and region & Length & $\begin{array}{c}\text { Upper- } \\
\text { glacier } \\
\text { downdraw }\end{array}$ & $\begin{array}{c}\text { Volume } \\
\text { displaced }\end{array}$ \\
& $\mathrm{km}$ & $\mathrm{m}$ & $\mathrm{km}^{3}$ \\
\hline Variegated Glacier, Alaska, U.S.A. & 20 & 50 & - \\
West Fork Glacier, Alaska, U.S.A. & 40 & 60 & 3.7 \\
Bering Glacier, Alaska, U.S.A. & 200 & 50 & - \\
Storstrømmen, North Greenland & 120 & 80 & 50 \\
Medveziy glacier, Pamirs, central Asia & 13 & 100 & 0.06 \\
Chiring glacier, Karakoram, Himalaya & 15.5 & 150 & $1-1.5$ \\
Bakaninbreen, Svalbard & 17 & 15 & 0.67 \\
Sortebræ, East Greenland & 52 & $\mathrm{Up}$ to 270 & $>22$ \\
& & & \\
\hline
\end{tabular}

margin of Sortebræ in a Landsat ETM panchromatic band 8 (15 m pixel size) image from August 1999. These icebergs have approximately rectangular, highly reflective upper surfaces, in contrast to the dirtier, debris-mantled upper surface of the trunk of Sortebræ, indicating that they have rotated during calving, exposing an englacial section. The exposed berg $c$ axis therefore represents the minimum possible thickness of the glacier front at this time, the measured thickness range being 160-230 m. For comparison, the snout of Storstrømmen is estimated to be $210 \mathrm{~m}$ thick (Reeh and others, 1994). The $300 \mathrm{~m}$ fjord depth estimate of Jiskoot and others (2001) was used for volume calculations, and assumed to represent the mean depth, but the error in this depth is unknown and the error estimate in Figure 6 accounts only for the error in the InSAR DEM over this area.

Mean elevation above sea level of the lower advanced trunk was $83 \pm 20 \mathrm{~m}$, which, with the estimated $300 \mathrm{~m}$ depth below sea level, gives a total estimated receiving-zone ice storage volume of $12.5( \pm>1.5) \mathrm{km}^{3}$ ( or $11.3( \pm>1.4) \mathrm{km}^{3}$ with the $10 \%$ correction) in February 1996 (these volume errors are minima because the error in fjord depth is not known). This value can be compared to the summer 1995 estimate of $7.7 \pm 1.3 \mathrm{~km}^{3}$ of Jiskoot and others (2001), who also used the $300 \mathrm{~m}$ depth estimate, though without knowledge of the pre-surge retreat. For comparison, the volume added to the front of Storstrømmen after a $10-12 \mathrm{~km}$ surge advance is estimated as $45 \mathrm{~km}^{3}$ (Reeh and others, 1994).

Of the estimated $21.9 \mathrm{~km}^{3}$ of ice transported from the reservoir area, $\sim 10.6 \pm 7.2 \mathrm{~km}^{3}$ of ice must therefore have been lost from the glacier complex to ablation (calving and melt) over the duration of the surge (24-35 months, from SAR image interpretation (Murray and others, 2002)). Given this high rate of loss, calving is likely to have dominated, implying a calving rate of $3.6-5.3 \mathrm{~km}^{3} \mathrm{a}^{-1}$. Little ice was stored above the pre-surge margin, and this may be related to the ease with which the glacier could advance where buoyancy acted to reduce effective pressure.

\subsubsection{Comparison with other surges}

The $\sim 22 \mathrm{~km}^{3}$ of ice displaced from the upper glacier by the surge can be compared to other surges for which there are comparable measurements (Table 2). The magnitude of the downdraw and the volume of ice transferred in this surge rank it as one of the larger surges on record. The calving rate of $3.6-5.3 \mathrm{~km}^{3} \mathrm{a}^{-1}$ between 1993 and 1996 can be compared to average annual calving rates of 10 and $13 \mathrm{~km}^{3} \mathrm{a}^{-1}$ for the two 
most productive ice-sheet outlet glaciers in East Greenland, Daugaard-Jensen and Kangerdlugssuaq Gletscher, and $\sim 30 \mathrm{~km}^{3} \mathrm{a}^{-1}$ for the largest outlet of the Greenland ice sheet, Jakobshavn Isbræ, on the west coast (Olesen and Reeh, 1969; Thomas and others, 2000). For the period of the surge, the calving output of locally draining Sortebræ would have made a significant contribution to the total calf-ice output from East Greenland.

\subsubsection{Quiescent-period accumulation}

The quiescent period of Sortebræ has been determined as 3949 years, from photographic evidence of a major surge in the 1950s, when a frontal advance of similar magnitude occurred (Jiskoot and others, 2001). Moraine and crevasse patterns from 1950s photographs indicate that the full trunk and the Upper and Lower Loop tributaries were also involved in this surge (Jiskoot and others, 2001).

The accumulation area for the Sortebræ complex (above $\sim 1150$ m altitude, excluding Sortebræ West which is believed to have an independent flow regime) was measured as $\sim 580 \mathrm{~km}^{2}$, at a mean elevation of $1930 \mathrm{~m}$. Annual accumulation was estimated from measurements made at an altitude of $2200 \mathrm{~m}$ on nearby Geike Plateau (Fig. 1) (Dall and others, 2001) as ranging between 0.4 and $0.9 \mathrm{~m}$ w.e. ( $\sim 0.46-1.0 \mathrm{~m}$ glacier ice), which is broadly consistent with the accumulation estimates of $0.3-0.45 \mathrm{~m}$ w.e. for this region (at an unspecified altitude) given by Ohmura and Reeh (1991). Assuming a crude constant lapse rate of accumulation with elevation, from zero at the ELA, the annual accumulation of ice is estimated as $0.20-0.45 \mathrm{~km}^{3} \mathrm{a}^{-1}$, though there is evidence from aerial photographs and Landsat images that avalanching from the steep surrounding mountains also contributes to accumulation. Given this range of accumulation rates, the required quiescent period is $49-110$ years, which is comparable to the observed quiescent period. The accumulation area consists of numerous short, steep glaciers that supply ice along much of the length of Sortebræ and its major tributaries (Fig. 1); hence travel time for ice from accumulation to reservoir area is likely to be short, and it is not unreasonable that the necessary volume could be recharged within the quiescent period.

\section{GONGLUSIONS}

Approximately $400 \mathrm{~km}^{2}$ of the post-surge surface of Sortebræ was mapped through interferometry. Ground-control point availability was limited to the area successfully phaseunwrapped, and those areas known not to have changed in height over the surge. This is likely to have been a major contributor to the relatively large error estimate of $20 \mathrm{~m}$ for the InSAR DEM. Trend-surface interpolation was found to be a method well suited to sparse contour data on glacier surfaces, though the magnitude of the error when the pre- and postsurge surfaces are differenced ( $31-70 \mathrm{~m}$ in this study) is such that this approach is only applicable to cases where the pre- to post-surge surface elevation change is large.

Results from the InSAR DEM, coherence products and the short-baseline differential interferogram show that an upper tributary of Sortebræ remained fast-flowing 610 months after the surge termination over the rest of the complex, and that in the period between the January and February interferograms, flow accelerated in the coherent area immediately downflow of the confluence. This led to a height error in this area through a failure of the assumption of constant velocity.

At least $21.9 \pm 8.6 \mathrm{~km}^{3}$ of ice $\left(24.3 \pm 9.5 \mathrm{~km}^{3}\right.$ total volume) was lost from the upper Sortebræ complex over the surge, of which approximately $11.3 \pm>1.4 \mathrm{~km}^{3}(\sim 12.5 \pm$ $>1.5 \mathrm{~km}^{3}$ volume) was stored in the lower glacier in early 1996, with $10.6 \pm 7.2 \mathrm{~km}^{3}$ lost to ablation, principally through calving. Ice was supplied from the Upper and Lower Loop and main trunk, which surged concurrently, and the Top Basin, which surged late. The InSAR DEM and coherence data suggest that the rapid retreat of the margin in the late/post-surge period was due to the front having advanced into water close to flotation depth, which is estimated as approximately $300 \mathrm{~m}$. In terms of the volume of ice involved, the surge of Sortebræ is amongst the largest for which equivalent measurements exist. According to calculations of accumulation rate, the measured surge volume loss could be replenished within the observed quiescent period, particularly given the short travel distances from a distributed accumulation area to a reservoir zone which lies largely within the ablation area.

\section{ACKNOWLEDGEMENTS}

H.P. was funded by U.K. Natural Environment Research Council studentship No. GT 4/99/120, and SAR data were provided through grants from the Royal Society, and through ESA and A. Shepherd of University College London through the VECTRA scheme. The Danish Meteorological Institute provided access to meteorological data. Two referees and the Scientific Editor, T. A. Scambos, provided useful comments.

\section{REFERENGES}

Chorley, R. J. and M. A. Haggett. 1965. Trend-surface mapping in geographical research. Inst. Br. Geogr. Trans., 37(1), 47-67.

Clarke, G. K. C. 1987. Fast glacier flow: ice streams, surging and tidewater glaciers. F. Geophys. Res., 92(B9), 8835-8841.

Dall, I., S. N. Madsen, K. Keller and R. Forsberg. 2001. Topography and penetration of the Greenland ice sheet measured with airborne SAR interferometry. Geophys. Res. Lett., 28(9), 1703-1706.

De Fazio, M. and F. Vinelli. 1993. DEM reconstruction in SAR interferometry: practical experiences with ERS-1 SAR data. In IGARSS '93, Better Understanding of Earth Environment, Tokyo, Japan, 18-21 August 1993. Proceedings. Vol. 3. New York, Institute of Electrical and Electronics Engineers, 1207-1209.

Dolgoushin, L. D. and G. B. Osipova. 1975. Glacier surges and the problem of their forecasting. International Association of Hydrological Sciences Publication 104 (Symposium at Moscow 1971 - Snow and Ice), 292-304.

Fatland, D. R. and C. S. Lingle. 1998. Analysis of the 1993-95 Bering Glacier (Alaska) surge using differential SAR interferometry. f. Glaciol., 44(148), $532-546$.

Fox, A. J. 1995. Using multiple data sources to enhance photogrammetry for mapping Antarctic terrain. Polar Res., 14(3), 317-327.

Geological Survey of Denmark and Greenland (GEUS). 1996. Topographic map of Greenland. (Scale 1:100 000.) Copenhagen, Geological Survey of Denmark and Greenland. (Sheets $68^{\circ} 01^{\prime} \mathrm{NW}, 68^{\circ} 02^{\prime} \mathrm{NE}, 69^{\circ} 02^{\prime} \mathrm{SW}$ and $69^{\circ} 03^{\prime} \mathrm{SE}$.)

Goldstein, R. M., H. A. Zebker and C. L. Werner. 1988. Satellite radar interferometry: two-dimensional phase unwrapping. Radio Science, 23(4), 713-720.

Haining, R. 1987. Trend-surface models with regional and local scales of variation with an application to aerial survey data. Technometrics, 29(4), $461-469$.

Hodgkins, R. and J. A. Dowdeswell. 1994. Tectonic processes in Svalbard tide-water glacier surges: evidence from structural glaciology. F. Glaciol., 40 (136), 553-560.

Jiskoot, H. 1999. Characteristics of surge-type glaciers. (Ph.D. thesis, University of Leeds.)

Jiskoot, H., A. K. Pedersen and T. Murray. 2001. Multi-model photogram- 
metric analysis of the 1990s surge of Sortebræ, East Greenland. F. Glaciol., 47(159), 677-687.

Kraus, K. 1993. Photogrammetry: fundamentalsand standardprocess. Fourth edition. Bonn, Fred. Dümmler Verlag. Vienna University of Technology.

Mohr, J.J., N. Reeh and S. N. Madsen. 1998. Three-dimensional glacial flow and surface elevation measured with radar interferometry. Nature, 391 (6664), 273-276.

Murray, T., J. A. Dowdeswell, D. J. Drewry and I. Frearson. 1998. Geometric evolution and ice dynamics during a surge of Bakaninbreen, Svalbard. $\mathcal{F}$. Glaciol., 44(147), 263-272 (Erratum: 45(150), 1999, 405.)

Murray, T., T. Strozzi, A. Luckman, H. Pritchard and H. Jiskoot. 2002. Ice dynamics during a surge of Sortebræ, East Greenland. Ann. Glaciol., 34, 323-329.

Ohmura, A. and N. Reeh. 1991. New precipitation and accumulation maps for Greenland. 7. Glaciol., 37(125), 140-148.

Olesen, O. B. and N. Reeh. 1969. Preliminary report on glacier observations in Nordvestfjord, East Greenland. Gronl. Geol. Undersøgelse, Rapp., 21, 41-53.

Oliver, M. A., R. Webster and J. Gerrard. 1989. Geostatistics in physical geography. Part 1: theory. Inst. British Geogr. N.S., 14, 259-269.

Raymond, C. F. 1987. How do glaciers surge? A review. F. Geophys. Res., 92(B9), 9121-9134.

Reeh, N., C. E. Bøggild and H. Oerter. 1994. Surge of Storstrømmen, a large outlet glacier from the inland ice of north-east Greenland. Gronl. Geol. Undersogelse, Rapp. 162, 201-209.
Rignot, E., K. C. Jezek and H. G. Sohn. 1995. Ice flow dynamics of the Greenland ice sheet from SAR interferometry. Geophys. Res. Lett., 22(5), 575-578. Squires, G. L. 1976. Practical physics. Second edition. Cambridge, McGraw-Hill Book Company (UK) Ltd.

Sturm, M. 1987. Observations on the distribution and characteristics of potholes on surging glaciers. F. Geophys. Res., 92(B9), 9015-9022.

Thomas, R.H. and 8 others. 2000. Substantial thinning of a major east Greenland outlet glacier. Geophys. Res. Lett., 27 (9), 1291-1294.

Unwin, B. and D. Wingham. 1997. Topography and dynamics of Austfonna, Nordaustlandet, Svalbard, from SAR interferometry. Ann. Glaciol., 24, 403-408.

Weidick, A. 1988. Surging glaciers in Greenland: a status. Grønl. Geol. Undersogelse, Rapp. 140, 106-110.

Werner, C., U. Wegmüller, T. Strozzi and A. Wiesmann. 2001. Gamma SAR and interferometric processing software. In Sawaya-Lacoste, H., ed. ERSENVISAT Symposium, 16-20 October 2000, Gothenburg, Sweden. Proceedings. Noordwijk, European Space Agency, 133-138.

Zebker, H. A. and R. M. Goldstein. 1986. Topographic mapping from interferometric synthetic aperture radar observations. 7. Geophys. Res. 91(B5), 4993-4999.

Zebker, H. A., P. A. Rosen, R. M. Goldstein, A. Gabriel and C. L. Werner. 1994. On the derivation of coseismic displacement fields using differential radar interferometry: the Landers earthquake. f. Geophys. Res., 99(B10), $19,617-19,634$.

MS received 3 September 2002 and accepted in revised form 29 April 2003 